\title{
Shifting concepts of urban spatial heterogeneity and their implications for sustainability
}

\author{
Weiqi Zhou • Steward T. A. Pickett • \\ Mary L. Cadenasso
}

Received: 12 October 2015/Accepted: 5 August 2016/Published online: 18 August 2016

(C) Springer Science+Business Media Dordrecht 2016

\begin{abstract}
Context Spatial heterogeneity has myriad influences on ecosystem processes, ecosystem services, and thus the sustainability of urban areas. It acts as a medium for urban design, planning, and management to determine how processes affecting sustainability can operate and interact. Therefore, how spatial heterogeneity is conceptualized and measured in cities is crucial for enhancing sustainability.

Objectives We show that the two most commonly used, but contrasting paradigms of urban ecology, ecology IN versus ecology OF the city, determine how spatial heterogeneity is thought of and used in different ways. We identify the key implications of these theoretical contrasts for the practice and assessment of sustainability in urban areas.
\end{abstract}

W. Zhou $(\bowtie)$

State Key Laboratory of Urban and Regional Ecology, Research Center for Eco-Environmental Sciences, Chinese Academy of Sciences, Beijing 100085,

People's Republic of China

e-mail:wzhou@rcees.ac.cn

S. T. A. Pickett

Cary Institute of Ecosystem Studies, Box AB, Millbrook, NY 12545, USA

\section{L. Cadenasso}

Department of Plant Sciences, University of California Davis, Mail Stop 1, PES 1210, One Shields Ave, Davis, CA 95616, USA
Methods We review and compare the different ways in which ecology IN versus ecology OF the city affect how to conceptualize, model and map urban spatial heterogeneity. We present a new framework to guide the comparison of spatial heterogeneity under the two paradigms.

Results and conclusion The integrative nature of this new framework becomes apparent under the ecology OF the city paradigm, because it recognizes the hybrid social and bioecological nature of heterogeneity in urban ecosystems. The hybrid approach to patchiness resonates with the three pillars of sustainability-environment, society, and economy. We exemplify how the more comprehensive and integrated framework of spatial heterogeneity under the ecology OF the city paradigm (1) supports more effective measurement and integration of the three components of sustainability, (2) improves management of heterogeneous urban ecosystems, and (3) satisfies calls for improved ecological tools to support urban ecosystem design.

Keywords Ecology in cities - Ecology of cities · Spatial heterogeneity · Urban sustainability . Urban design

\section{Introduction}

With the majority of the world's population already living in cities, and the projected increase in both urban population and urbanized land cover, how cities, 
suburbs, and exurbs can contribute to global sustainability is a pressing concern (Grimm et al. 2008; Wu 2013; Childers et al. 2014; Pickett and Zhou 2015). Indeed, whether and how urban regions themselves can become more sustainable is an urgent question. Spatial heterogeneity is one of the fundamental concepts in contemporary ecology (Scheiner and Willig 2011). It has myriad influences on ecosystem processes, ecosystem services, and thus the sustainability of urban areas (Pickett and Cadenasso 1995; Turner et al. 2001; Cadenasso and Pickett 2008; Wu 2010). Spatial heterogeneity in social-ecological systems (SES) itself constitutes an important component of adaptive capacity for resilience (Walker et al. 2004; Wu and Wu 2013; Zurlini et al. 2013). Furthermore, it mediates environmental equity and many other important adaptive capacities that can affect resilience, and through it, the attainment of sustainability (Yohe and Tol 2002; Carpenter et al. 2005). Therefore, spatial heterogeneity in urban systems acts as a medium for urban design, planning, and management to determine how processes affecting sustainability can operate and interact (Band et al. 2005; Jenerette et al. 2006; McDonnell and Hahs 2009; Chowdhury et al. 2011; Huang et al. 2011; Zhou et al. 2011a; Boone and Fragkias 2012; Pickett et al. 2016). How researchers frame the measurement of heterogeneity can affect how features promoting sustainability are modeled, assessed, and planned in cities, suburbs, and exurbs. Conceptual framing is fundamental to solving urban problems and facilitating application (Koskela 2008).

There are two commonly used paradigms to describing and quantifying the ecological structures and processes of urban systems: the "ecology in cities," and the "ecology of cities" (Grimm et al. 2000; McDonnell and Hahs 2009). These two paradigms have become familiar enough to be used in introductory urban ecology textbooks (e.g., Gaston 2010; Douglas and James 2015). These paradigms suggest contrasting ways of conceiving the spatial heterogeneity of urban mosaics, and hence, understanding how heterogeneity applies to sustainability. This paper articulates for the first time how the paradigms of ecology in the city and ecology of the city conceptualize, model and map urban spatial heterogeneity in different ways, and the key implications of these theoretical contrasts for the practice and assessment of sustainability in urban areas (Fig. 1). This is an important effort in light of the relative neglect of ecological perspectives in considering sustainability in social-ecological landscapes (Burger et al. 2012). The earlier ecology in the city paradigm emphasized biological structures and conservation within the urban fabric (Pickett et al. 1997; McPhearson et al. 2016). We present a new framework that exposes the contrast in how spatial heterogeneity is treated differently under the more inclusive ecology of the city paradigm. The framework explores the improvements in understanding, modeling and mapping spatial heterogeneity that come from the shift toward conceptualizing ecosystem heterogeneity as a hybrid of social and bioecological components. The framework recognizes this shift as a fundamental component of the ecology of the city paradigm. The integrative nature of heterogeneity exposed by this new framework, and the associated improvements in the measurement of patchiness, resonates with the three realms or pillars of sustainability-environment, society, and economy (Curwell et al. 2005; Jenks and Jones 2010). This resonance emerges from the fact that the framework recognizes structures representing each of the three realms. We exemplify how the more comprehensive and integrated framework of spatial heterogeneity under the ecology of the city paradigm (1) supports more effective measurement and integration of the three components of sustainability, (2) improves management of heterogeneous urban ecosystems, and (3) relates better to design in urban ecosystems.

\section{Urban spatial heterogeneity and sustainability}

Urban heterogeneity consists of spatial differentiation in the physical, biological, and social structures of urban areas (Cadenasso et al. 2007; Pickett et al. 2016). Social scientists, urban designers, and urbanists consider spatial heterogeneity to be one of the fundamental aspects of urban systems (Luck and $\mathrm{Wu}$ 2002; Cadenasso et al. 2006; McGrath et al. 2007; Pickett et al. 2013). Spatial heterogeneity can take many forms in cities. Patches exist as differences in biological and physical features such as vegetation, surface permeability, and the kinds and density of infrastructure (Band et al. 2005). Social heterogeneity is exemplified by wards, zones, blocks, and neighborhoods. Land use types are additional examples of urban heterogeneity based on human 
Fig. 1 Diagram of the argument that contrasting paradigms of urban ecology research entail different approaches to conceptualizing and modeling spatial heterogeneity, and that these ultimately inform different applications of urban ecology to sustainability

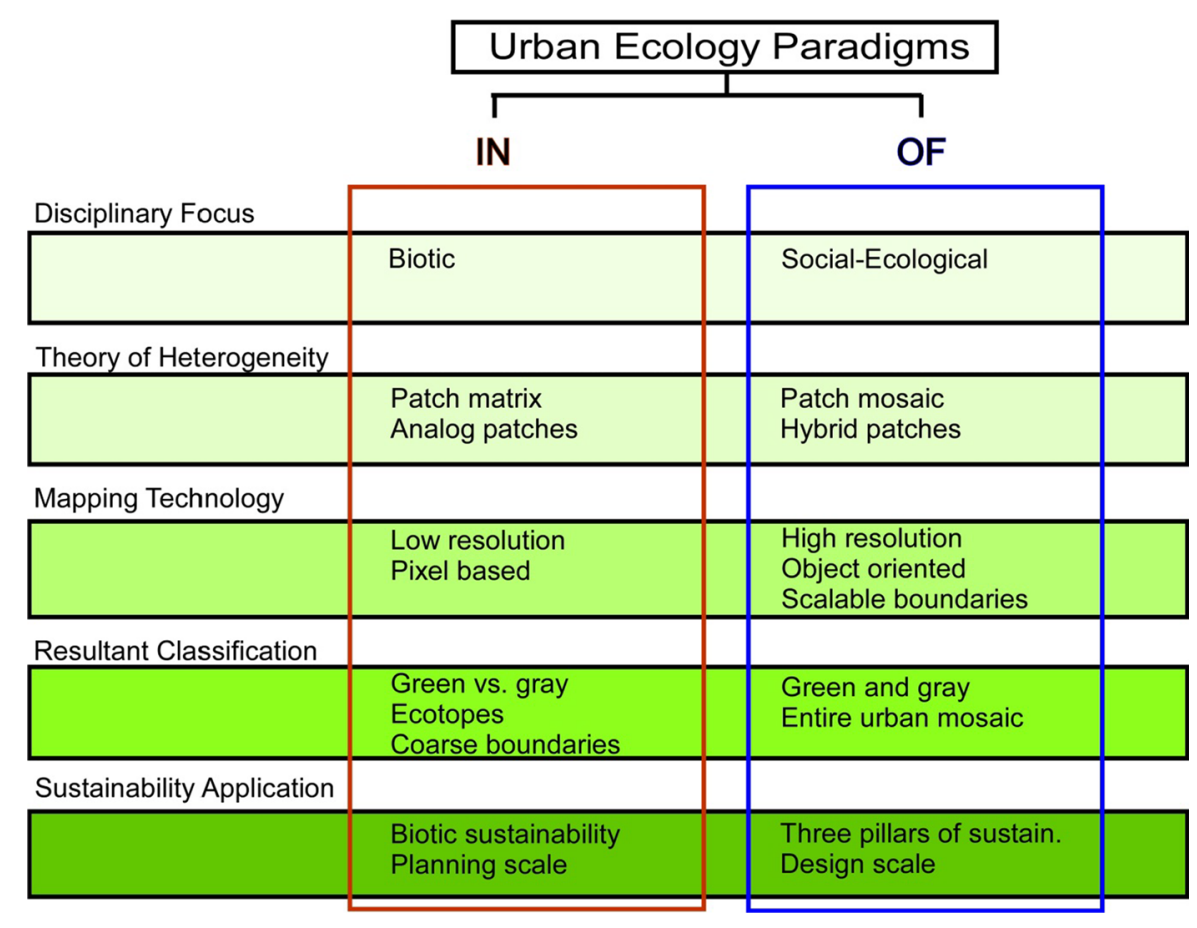

activities as the criterion discriminating patches. Heterogeneity of land uses and social functions exists as particular mixtures of residential types, property regimes, or economic activities (Grove and Burch 1997). Such spatial differentiation emerges from the existence and divergence of social groups, from economic clustering, and the development of architectural enclaves (Shane 2011). The scales and patterns of these various heterogeneities can affect the human and social capital or capacities in an urban area, the spread or isolation of physical hazards and social vulnerabilities, environmental inequity, and the boundaries among management units regardless of land ownership (Boone and Fragkias 2012).

Heterogeneity is key to sustainability because spatial differentiation can appear in each of the three realmsenvironmental (Zurlini et al. 2013), social (Chowdhury et al. 2011), and economic (Irwin 2010). Many have argued that sustainability is a tripartite suite of societal goals, involving integrity and integration of environmental, social, and economic structures and processes (Turner 2010; Wu 2010; Boone and Fragkias 2012; Redman 2014). Of course, urban systems will not be sustainable in the sense of limiting resource extraction and waste disposal to local sources and sinks only within their boundaries (Wu 2013). For this reason, urban sustainability is best conceived as a trajectory toward- or away from-the ideals expressed by a normative, social decision-making process (Childers et al. 2014).

There are many steps between the broad conception of sustainability and the practical improvement of a system (Koskela 2008). This is particularly true in urban systems, where effectively integrated conceptions and data sets connecting the biophysical environment, social processes, and economic drivers are still being developed. Spatial heterogeneity in urban systems determines how processes affecting sustainability operate and interact (Band et al. 2005; Jenerette et al. 2006; McDonnell and Hahs 2009; Boone and Fragkias 2012). Therefore, how spatial heterogeneity is conceptualized and measured in cities is crucial for enhancing urban sustainability (Burger et al. 2012; Zurlini et al. 2013). The two framing paradigms - the ecology in cities and the ecology of cities (Grimm et al. 2000; Pickett et al. 2008; McDonnell and Hahs 2009), can determine how the insights of heterogeneity are ultimately applied to sustainability.

\section{The earlier framework: measuring spatial heterogeneity under the ecology in cities paradigm}

The first of the contrasting paradigms to develop was the ecology in cities (Grimm et al. 2000; McDonnell 
and Hahs 2009). This approach was the earliest to emerge, and has a long history in Europe and Asia. After World War II, with the need to rebuild damaged cities, inventories of vacant lands and the plants and animals they supported were undertaken (Sukopp et al. 1995). An immediate concern was to contribute to the effective planning in cities, and to retain biological amenities within them (Breuste et al. 1998). The general approach under this paradigm is to focus on biologically dominated locations in urban areas (Stearns and Montag 1974). The predominant disciplinary motivation is from fields such as organismal biology, biological ecology, conservation, and wildlife biology ( $\mathrm{Wu} 2014)$.

Analog patches under the ecology in cities

The concerns of the ecology in cities paradigm result in a focus on biological patch types that are analogs of habitats familiar outside of cities. It is such patches that are traditionally accorded conservation and ecological value in urban systems (Platt et al. 1994). Forests (McDonnell and Hahs 2008), desert, wetland (Ehrenfeld 2000), and grassland patches (Golubiewski 2006) are thus common study subjects (Fig. 2a, b). Consequently, the sampling methodologies developed in wild and rural instances of those systems are simply transported intact to their analogs in cities and suburbs. There have been refinements in method, such as developing inconspicuous plot marking strategies, or the use of global positioning systems to facilitate repeated sampling of urban research plots, while making them invisible to the merely curious or the intentionally destructive.

When social attributes of the system are considered by the ecology in cities approach, aggregate and coarse scale parameters are often chosen (McIntyre et al. 2000). The adjacent territory to the focal biological patch was sometimes characterized by such things as human population density, degree of urbanization, land use types, or road density (Medley et al. 1995; McDonnell et al. 1997; Zhou et al. 2011b). Social scientists were apparently rarely consulted in most such characterizations; rather, commonly or publically available data sources were employed following the intuition of ecologists about the relevant social or built contexts (Zipperer et al. 2000). The built or socially dominated patches became the "other" in a simple dichotomous contrast with the biological
Fig. 2 Conceptualizing, modeling, and mapping spatial heterogeneity of urban systems under the two paradigms, ecology in the city and ecology of the city. a False-color infrared aerial photo of an urban landscape in metropolitan Baltimore, MD, USA that serves as the base layer for the different models and maps in subsequent panels; b with the ecology in the city paradigm, urban systems are frequently mapped as biologically dominated patches, shown here in green, embedded within the built matrix, which is considered to be relatively homogeneous; c Land cover/land use classification from $30 \mathrm{~m}$ Landsat TM data; $\mathbf{d}$ Land cover/land use classification from $0.6 \mathrm{~m}$ resolution aerial imagery; e Patches generated from the land cover/land use classifications in panel $c$; f: Patches generated from land cover classifications in panel $d$; $\mathbf{g}$ Parcels as hybrid social patches, where the boundaries of parcels were overlaid on the aerial photo; $\mathbf{h}$ the hybrid patches derived from the $0.6 \mathrm{~m}$ resolution imagery based on the HERCULES classification

patches of interest (Fig. 2b). This conceptual choice means that the environmental pillar of sustainability will be represented by those biologically dominated patches in cities. Any biologically generated services will only be recognized if they are associated with such patches. Although ecosystem or ecological services may exist outside of patches identified as ecologically defined, they will not be visible to such a dichotomous classification approach.

Modeling approaches to heterogeneity under the ecology in cities

Two kinds of models, the patch-corridor-matrix and the patch mosaic are generally used by ecologists to represent the spatial heterogeneity of landscapes. Under the ecology in cities paradigm, the patchcorridor-matrix model has usually been adopted to represent the spatial heterogeneity of urban landscapes (Cadenasso 2013). This model stems from island biogeography and metapopulation theory and is exemplified by the initial theory of American landscape ecology. With this model, urban areas are conceived of as a relatively homogeneous matrix of developed lands, embedded with discrete and nonexhaustive, biologically dominated patches, such as forests and parks (Sukopp et al. 1995). These biologically dominated green and "natural" patches are generally the research foci, and the matrix is taken to be the hostile surroundings or simplified as a source of disturbance (e.g., Sukopp et al. 1995; Kong et al. 2010; Zhou et al. 2011b), in order to examine the effect of the 

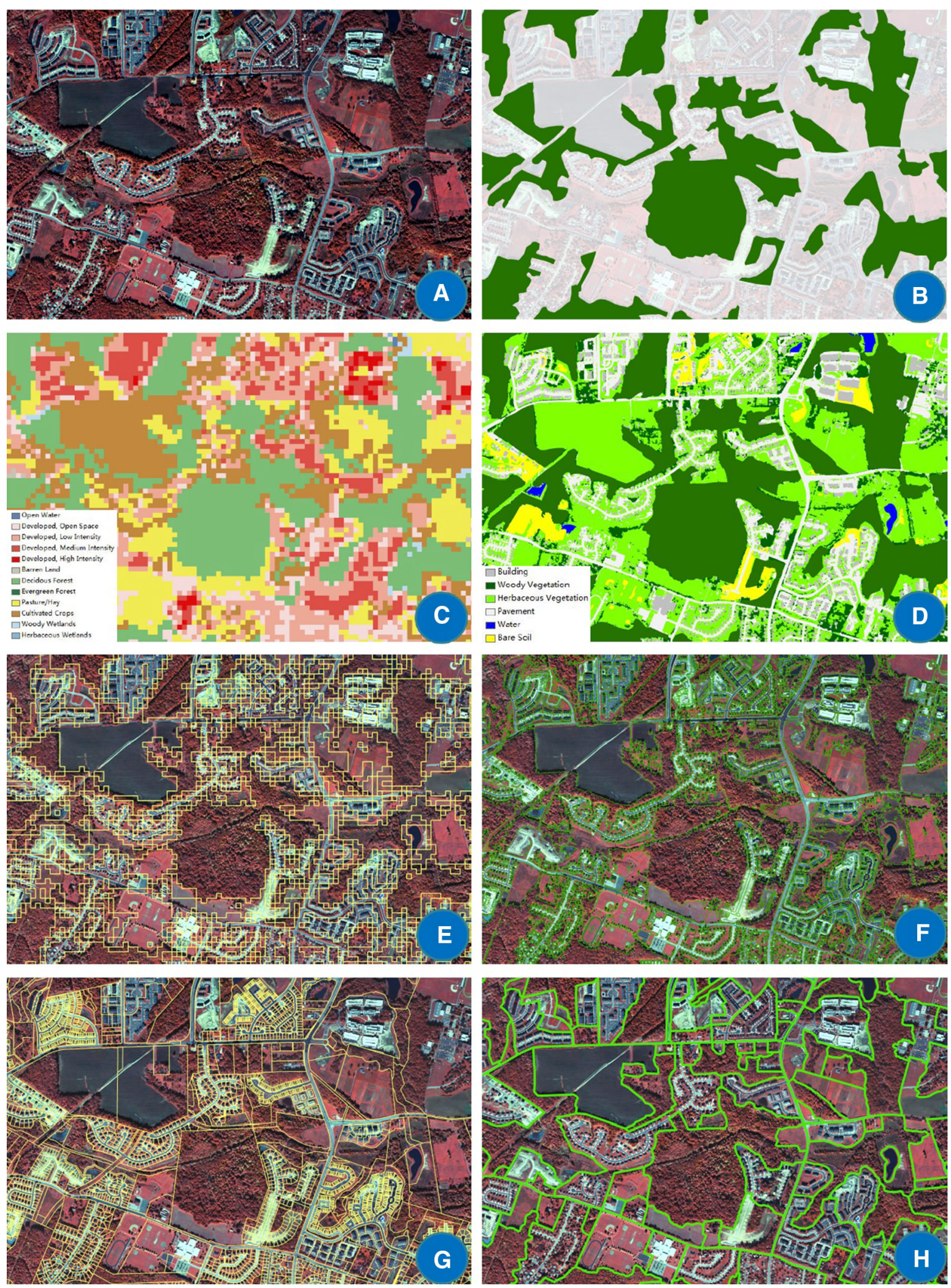
city on the ecology of organisms (Medley et al. 1995; Fig. 2b).

Mapping spatial heterogeneity under the ecology in cities

Because spatial heterogeneity in cities is frequently represented as land use/land cover, patches have typically been generated from thematic land use/land cover maps (Turner et al. 2001; Luck and Wu 2002). These maps are derived from remotely sensed data, by grouping adjacent pixels with the same category of land cover/land use (Turner et al. 2001; Luck and Wu 2002). This approach can provide automatic patch delineation and classification. Methods employed in the past have been largely based on available mediumand low-resolution datasets, for example, the widely available and long-term record provided by Landsat (e.g., Luck and Wu 2002; Buyantuyev et al. 2010).

Land use/land cover data derived from remotely sensed imagery with medium spatial resolution works well, in general, for mapping relatively large biological patches such as forest remnants, agricultural fields, and large golf courses (Buyantuyev et al. 2010; Jenrette and Wu 2001; Qian et al. 2015b), which are generally the focal patches with studies of ecology in cities (Fig. 2c, e). These data and mapping approaches also work well for the matrix, that is, the surrounding developed environments (Fig. 2c, e). Dichotomous division of the landscape into biologically dominated patches versus the built matrix is served by this technique. The resultant classifications may have a low categorical resolution, in which developed areas are simplified as the relatively homogeneous built matrix, sometimes treated as background or degree of disturbance (Medley et al. 1995; McDonnell et al. 1997; Zhou et al. 2011b), which are in fact very heterogeneous in land cover/land use (Fig. 2).

Land cover classification under the ecology in cities

Under the ecology in cities paradigm, the spatial heterogeneity of urban ecosystems is classified using the thematic land cover/land use maps generated from low and medium spatial resolution imagery (Fig. 2c), as described above. The technique generates patches by grouping similar and spatially adjacent pixels with the appropriate pre-determined category of land cover/land use (Fig. 2e). While the boundaries of the patches tend to be coarse due to the low spatial resolution of the data, patches in general work well for relatively large, biologically dominated, analog patches (e.g., forest patches, agricultural fields), which are the foci of studies following the ecology in cities paradigm.

This approach, however, has limitations for areas that integrate built and non-built areas, which is a typical characteristic in urban areas (Fig. 2e). This is because, first, the medium spatial resolution data are inadequate to capture the fine-scale spatial heterogeneity within these integrated areas. But more fundamentally, it is also due to how the spatial heterogeneity of urban ecosystems is conceptualized and modeled under the ecology in cities paradigm (Cadenasso et al. 2007). Examining the coarselyconceptualized patches under the ecology in cities approach, using high spatial resolution imagery reveals internal complexity that may have ecological significance (Cadenasso 2013). With very high spatial resolution data, the fine-scale spatial heterogeneity can be well characterized. For example, lawns and trees can be clearly separated from buildings and paved or bare surfaces (Fig. 2d, f). However, such discrimination in and of itself does not represent the hybridity of the patchiness of the urban systems, as non-built components are separated from the adjacent building, for example, or lawns and trees are not linked with the building within a parcel. As urban ecologists and urban designers are increasingly interested in the reciprocal interactions between built and non-built components (Cadenasso 2013; McGrath 2013; Redman 2014), there is a need to shift the paradigm in conceptualizing, modeling, and mapping spatial heterogeneity of urban systems. This interest is promoted by the ecology of cities paradigm, as described next.

\section{A new framework: measuring spatial heterogeneity under the ecology of cities paradigm}

We turn now to a new framework for measuring spatial heterogeneity under the other major paradigm for urban ecology, the ecology of cities. The ecology of cities approach was introduced to herald a more integrative, interdisciplinary approach to urban ecology than had characterized American ecological 
science before that time (Grimm et al. 2000; McPhearson et al. 2016). In other words, the approach is concerned not just with biological versus built patches. Rather, it aims to represent both a spatially and a conceptually comprehensive view of an urban system. The patches that had, under the ecology in cities paradigm, been treated as a simple "other" are now disaggregated into more specific patches that are hypothesized to be relevant to the functioning of the urban system (e.g. Cadenasso et al. 2007; Zhou et al. 2014) (Fig. 2b vs. f). These patches are defined as hybrid compositional elements, including both built and non-built components.

Hybrid patchiness under the ecology of cities

The ecology of cities paradigm takes a social-ecological rather than an organismal stance to spatial heterogeneity. Even the theory of the built environment has been characterized as focusing on a socialecological system (Moffatt and Kohler 2008). Ecology of cities describes spatial heterogeneity using hybrid compositional elements. The hybridity of individual, structurally defined patches includes both built and non-built components (Moffatt and Kohler 2008; Palazzo and Steiner 2011). Therefore, characterizing hybrid patches would require discriminating such elements as individual buildings, driveways, lawns, and individual trees, such hybridity can address structure along three complex dimensions for any given area simultaneously: the proportion and kind of vegetative cover; the proportion and nature of ground surfaces; and the proportion and nature of built structures (Cadenasso et al. 2007). The High Ecological Resolution Classification for Urban Landscapes and Environmental Systems (HERCULES) classification is an example of a tool that operationalizes this fundamental assumption of social-ecological hybridity under the ecology of the city paradigm. It is certainly possible to use other land cover classifications (e.g. Larondelle et al. 2014). In the HERCULES case, patches differ from one another by the proportion of these three major kinds of cover elements considered together. They are thus hybrid patches, and not strictly biological, or strictly social, or strictly pervious/impervious (Cadenasso et al. 2007). Hybridity reflects the origins of patch structure and functioning from both biophysical and social-economic sources. For example, property parcels in the same neighborhood built at the same time may have similar proportional cover of vegetation and buildings, and the resident households may have similar social-economic status and management strategies (Grove et al. 2014).

The structural features of hybrid patches clearly reflect biological processes, such as plant invasion, survival, and succession (Adams 2005), as well as features that clearly express social criteria (Machlis et al. 1997), such as zoning and construction regulations (Ben-Joseph 2005) or investment in pavement or buildings (Irwin 2010). Patches may contain more than one kind of feature. For example, patches can contain different types and amounts of features such as buildings, impervious surfaces, and trees (Cadenasso et al. 2007). The patches delimited using this comprehensive approach emphasize structure based on the three defined dimensions simultaneously. The patches differ in the degree of each major component, not an "on/off" dichotomy. Ecology of the city accepts, for example, that a patch can have fine-scale characteristics of traditional urban, forest, and agricultural (e.g. grass) classes simultaneously (Fig. 2g, h).

Modeling approaches to heterogeneity under the ecology of cities

Hybrid patches require a different modeling strategy than analog patches. Under the ecology of the city paradigm, the spatial heterogeneity of urban landscapes has been represented by the patch mosaic model (Forman 1995; Pickett and Cadenasso 1995; Wu 2002). With the patch mosaic model, urban landscapes are represented as mosaics of mutually exhaustive, discrete patches. To be able to address hybridity, patches must be identified and mapped based on multiple criteria such as variation in plant community composition or land use/land cover. Patches can also be delineated based on a contrast in an ecological process, such as rates of denitrification. Consequently, different criteria, practices, and processes may suggest different patch mosaics, depending on the specific research or management question addressed (Cadenasso et al. 2003).

Other kinds of structure, such as identity and function of social institutions, street and highway networks, property regimes, and zoning can all be represented as additional layers. In addition, more specific information about household and institutional decision making, or the structure of social or built networks, or the distribution of social attitudes and 
actions can complement the structural classification as well.

The contrast between the familiar land use categories and hybrid patches illustrates the difference between improvement in spatial resolution and a shift in conceptual resolution. A variety of patches delineated using the familiar criteria of land use may all be classified as residential, but these patches may differ from one another in the kind and amount of vegetation, the details of the surface covers, and the proportion and configuration of buildings (Cadenasso et al. 2007). A multidimensional approach that exposes the differences within residential land use classes, especially beyond the refinement based on building density, is a conceptual refinement, not just a refinement in spatial resolution of the data. The concepts used in modeling patches are the fundamental assumptions on which patch delimitation is based. The spatial data resolution is a part of the tool kit that can be used to generate either coarsely parsed or highly conceptually resolved patch mosaics. Spatial and conceptual resolution are different.

Mapping spatial heterogeneity under the ecology of cities

Research questions using the ecology of cities paradigm, frequently require an understanding of fine-scale heterogeneity, for example, discriminating such elements as individual buildings, driveways, individual trees, and lawns (Cadenasso et al. 2007; Zhou et al. 2008). To adequately map these individual structural elements, very high spatial resolution imagery is preferred (Zhou and Troy 2008; Qian et al. 2015a). With the continuous launching of new commercial satellites and advances in aerial photogrammetry, very high-spatial resolution imagery is becoming widely available and affordable.

In addition to the need for high spatial resolution data, studies under the ecology of city paradigm employ new approaches for hybrid patch mapping. The traditional approach, grouping adjacent pixels with the same category of land cover/land use generally creates patches of single landscape features (e.g., paved surfaces, or lawns), where built and nonbuilt components are separated (Fig. 2e). This traditional approach is inadequate to capture the hybridity of the patches. Therefore, there is a need to apply hybrid approaches such as that illustrated by
HERCULES (Cadenasso et al. 2007), to quantify the fine-scale heterogeneity in urban landscapes that integrate the built and non-built components of the system, to better understand their reciprocal interactions (Grimm et al. 2000; Zhou et al. 2014; Qian et al. 2015b).

A hybrid approach that capitalizes on the strengths of visual interpretation and object-based image analysis can serve this integrative need (Zhou et al. 2014). Compared to digital image processing approaches, visual interpretation is better for delimiting hybrid patches that incorporate built and non-built components (Zhou et al. 2014). Meanwhile, recent advances in object-based image analysis allow obtaining highly accurate urban land cover data from high spatial resolution imagery to discriminate individual structural components of patches such as individual trees, lawns, and buildings (Zhou et al. 2008). With this hybrid approach, mapping spatial heterogeneity under the ecology of cities consists of two steps. First, patches are generated through visual interpretation, based on a set of rules. These patches typically contain a mix of built and natural land cover features (e.g., Fig. 2h). These within-patch land cover features are then classified using object-based image analysis, in which the delineated patches serve as pre-defined boundaries for finer-scale segmentation and classification (Zhou et al. 2014). Finally, patches are classified based on the within-patch proportional cover of features.

This hybrid approach integrates the ability of humans to detect pattern with an object based image analysis that accurately and efficiently quantifies the components that give rise to that pattern, and therefore provides an effective means for hybrid patch mapping and classification (Zhou et al. 2010, 2014).

Land cover classification under the ecology of cities

With the ecology of cities paradigm, urban ecosystems are represented by a mosaic of hybrid patches that each contains a mix of built and natural land cover features (Fig. 2f). These patches can use pre-defined boundaries of social patches such as parcels or census block groups, or biophysical boundaries such as watersheds, or delineated according to certain classification systems such as HERCULES (Cadenasso et al. 2007; Zhou et al. 2010, 2014). These patches can be classified, for example, based on within-patch types 
and proportion of land cover features (Cadenasso et al. 2007; Zhou and Troy 2008). This can be done either through visual interpretation, or based on identification of land cover features with very high spatial resolution generated from object-based image analysis (Zhou et al. 2010, 2014). With the object-based approach, the resultant classifications of land cover features not only provide more accurate patch classification (Zhou et al. 2010), but also provide more flexibility in patch classification, which was envisioned as a key feature in developing HERCULES (Cadenasso et al. 2007). Such flexibility allows different classification schemes with contrasting categorical resolutions to be developed based on diverse research questions (Zhou et al. 2014). For example, if either research, management, or design needs more or less categorical resolution in land cover features, the classes can be easily obtained by recoding the continuous percent cover of the land cover feature(s) within a patch.

Additionally, the integration of built and non-built areas into social-ecologically relevant patches may also correspond to patches having social significance (Zhou et al. 2014). For example, neighborhoods that were built at the same time, especially if they were built by the same developer, will likely have similar amounts of woody and herbaceous vegetation, and building cover. Neighborhoods with similar structure would be captured as a single patch, which may also represent social organization in the community, for example, a neighborhood association. This ability to assess the degree of match between the ecological and social datasets is crucial for implementing integrated social-ecological research. In addition, hybrid patch boundaries often coincide with aggregations of property parcels, which are individually the basic social land management unit (Grove et al. 2014). Classifications that do not integrate built and non-built components would not be able to capture this reciprocal relationship. In fact, patches can also be classified based on their social attributes by overlaying additional social data layers, or a combination of both biophysical and social attributes.

\section{The ecology of cities and hybrid heterogeneity for urban sustainability}

The pursuit of urban sustainability will be affected by the spatial heterogeneities in each of its three realms, i.e., environment, society, and economy. In each of the three realms, contexts, processes, and hazards exist, and these will either constrain or enhance sustainability (Childers et al. 2014). We have traced the implications of two frameworks (Fig. 1) for measuring urban spatial heterogeneity under the two contrasting paradigms of urban ecology, starting with their differing conceptions of spatial heterogeneity, through the modeling approaches each entails, and ending with the most appropriate methodologies for generating classifications and maps at spatial and categorical resolutions suitable to the goals of each paradigm. A social-ecological systems (SES) framework is highly relevant to identifying and achieving normative sustainability goals because the three realms of sustainability span both social-economic and biophysical features (Redman 2014). However, our analysis suggests that the lens through which spatial heterogeneity is viewed within an SES will be important for the practical pursuit of sustainability.

Spatial heterogeneity under ecology of cities reflects integrated sustainability goals

The ecology in cities paradigm focuses on the persistence and resilience of biotically dominated patch types or ecotopes (McPhearson et al. 2016). Patches are conceived simply as either bioecological resources and services, versus the contrasting, and usually biotically hostile, social and built matrix (Sukopp et al. 1995). Such dichotomous classifications are well supported by the patch-corridor-matrix modeling approach (Cadenasso 2013), and coarse spatial thematic imagery allows planning maps to portray the starkly contrasting categories. Maps of city-wide or metropolitan park systems or plans, and plans for metropolitan greenbelts exemplify this dichotomous approach. Furthermore, the image analysis approaches operate at the coarse spatial scales useful for city-wide or regional urban planning that identifies and maps forest, wetland, grassland, or other biotically-dominated patches (e.g., Yaro and Hiss 1996). These are resources or locations of concern in a planning-withnature or ecological planning strategy (Sukopp and Weiler 1988; Sukopp et al. 1995).

As useful as such an approach is, and as valuable as it has been for highlighting ecologically sensitive or service-providing areas that require protection or restoration in the urban fabric (Haase et al. 2014), it 
is a limited approach to sustainability in the broader sense. With ecology in the city, the approach yields classifications, analyses, and maps that support only the environmental pillar of sustainability.

In contrast, the ecology of cities paradigm promotes improvements in the assessment of heterogeneity that can better support tripartite (e.g., Redman 2014) sustainability goals. It does this in several ways. First, it recognizes that patches, the basic unit of spatial heterogeneity, are hybrids of socially mediated and biophysically mediated elements, including vegetation, buildings, and unvegetated surfaces, whether paved or bare. Second, it supports spatial modeling that exposes the detailed structure of the entire urban mosaic, rather than representing cities as two-phase systems of bioecological patches versus a built and social matrix. Finally, the ecology of cities pays attention to all elements of the spatial mosaic, and helps connect ecological with other disciplinary approaches that have addressed the city as a complex whole (McPhearson et al. 2016). Consequently, the heterogeneity revealed by the land modeling approaches that reflect the ecology of cities paradigm can be used to evaluate and track structural features that support sustainability in the bioecological realm, as well as in the social and economic realms (e.g., Pincetl 2010). This inclusiveness within patches is particularly relevant to the goal of helping to facilitate sustainability in urban systems. The integrative nature of the ecology of cities, and its approach to patchiness resonates with the three pillars of sustainability (Buijs et al. 2010). Ecology of cities achieves this resonance by including in its patch classifications structures that represent environment, society, and economy. The framework under the ecology of cities paradigm can help flesh out the spatial and functional aspects of integrated socialecological systems. It offers novel mechanistic detail to this overarching coupled-system conception.

Management implications of comprehensive patch assessments

The contrasting spatial modeling approaches under the two paradigms have divergent implications for management. Under the ecology in cities paradigm, management focus is on the large, discrete, biotically-dominated patches within the urban matrix. These areas have been widely recognized to have value for ecosystem services; however, this focus neglects sites that the ecology of cities paradigm would not a priori exclude. Indeed, the framework under the ecology of cities paradigm represents the spatial heterogeneity of urban systems as comprehensive mosaics. There should be no "blank spaces" on maps of urban heterogeneity under the ecology of cities paradigm. Importantly, "left over spaces" such as derelict lands, slivers of lightly or unmanaged land on the edges or rarely visited fringes of parcels, must also be included in ecological maps of urban mosaics for purposes of management (Troy et al. 2007; Pickett 2010; Qian et al. 2015a). These sites may contribute to biodiversity, stormwater management, microclimate mitigation and other services. Similarly, yards, lawns, and gardens can contribute important ecosystem services in urban regions (Golubiewski 2006), even though such sites are not considered primarily as ecotopes or biotic patches that support conservation.

The approach for measuring spatial heterogeneity under the ecology of cities paradigm suggests that management for the public good may be impaired if the focus is confined to public lands. As an example, many cities (e.g., Baltimore, New York City, and Los Angeles) have established Urban Tree Canopy (UTC) goals as a part of their sustainability plans to achieve such benefits as microclimate regulation, stormwater management, and cultural ecosystem services. The UTC planning in Baltimore, Maryland, has provided a model that has been adopted by many other cities (Locke et al. 2010). The Baltimore UTC plan calls for a doubling of the city's tree canopy, from the current $21 \%$ to approximately $40 \%$ by 2030 . Spatial analysis of the tree cover in Baltimore documented the existing patches of trees, patches of herbaceous vegetation, and the area potentially available for planting, that is, sites not covered by streets, parking lots, or buildings (Troy et al. 2007). Superimposing the parcel boundaries on these patch maps led the city planners to conclude that private property owners and renters would have to be engaged to achieve the new canopy goals. There was simply not enough land in the public domain to support enough new tree canopy to double the city's tree cover. These plans must rely on the involvement of private land owners and managers who are responsible for $70 \%$ of the area of many municipalities. Understanding the details of patches outside of the large parcels that an ecology in the city approach would have emphasized was required for an effective 

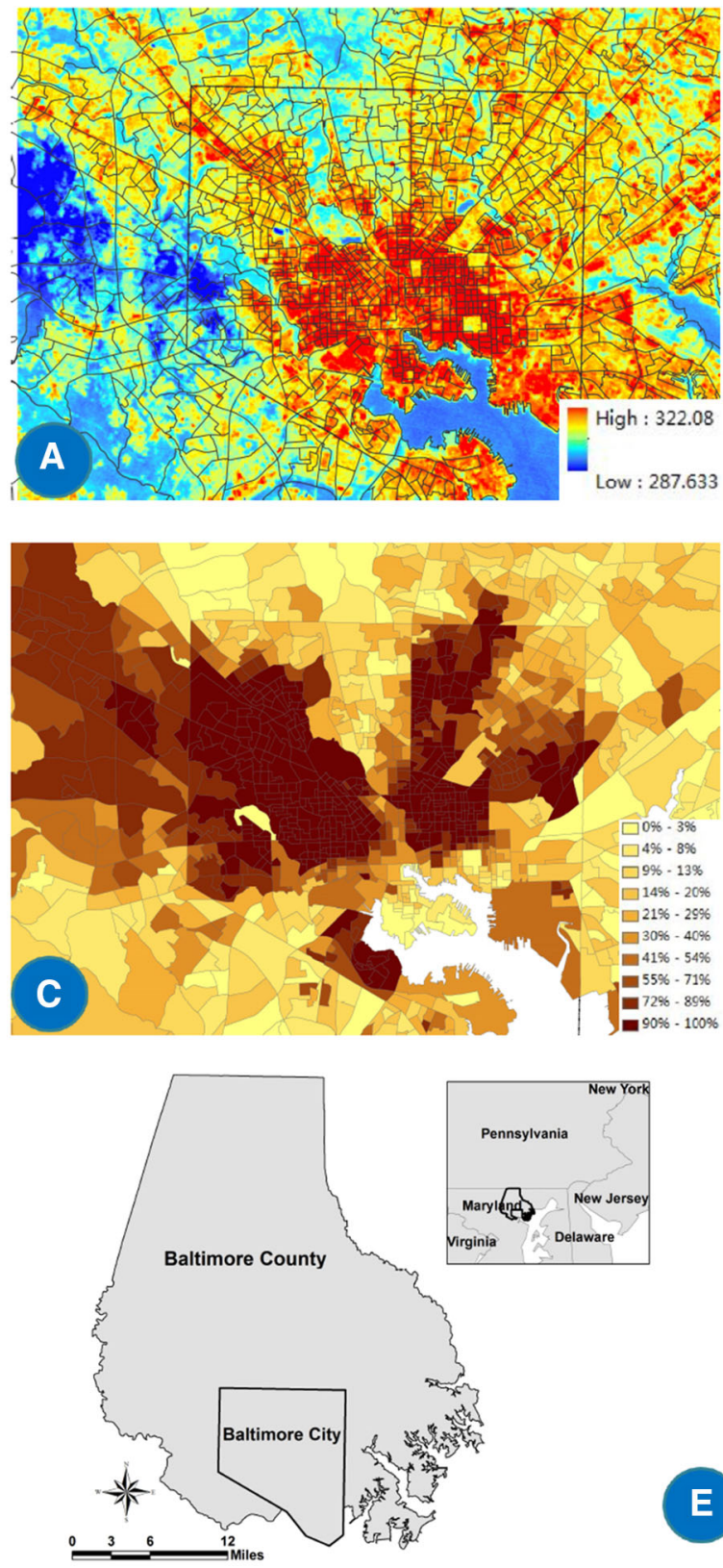

E

Fig. 3 Variation in land surface temperature (LST), tree canopy, race, and income across the core of the Baltimore MD, USA, metropolitan area. a Gradient of LST where dark red is the warmest and dark blue the coolest. b Distribution of tree canopy cover, decreasing from dark green to light green. c The

management plan, and suggested that active engagement with diverse and differentially environmentallyaware neighborhoods and property holders was needed (Troy et al. 2007).
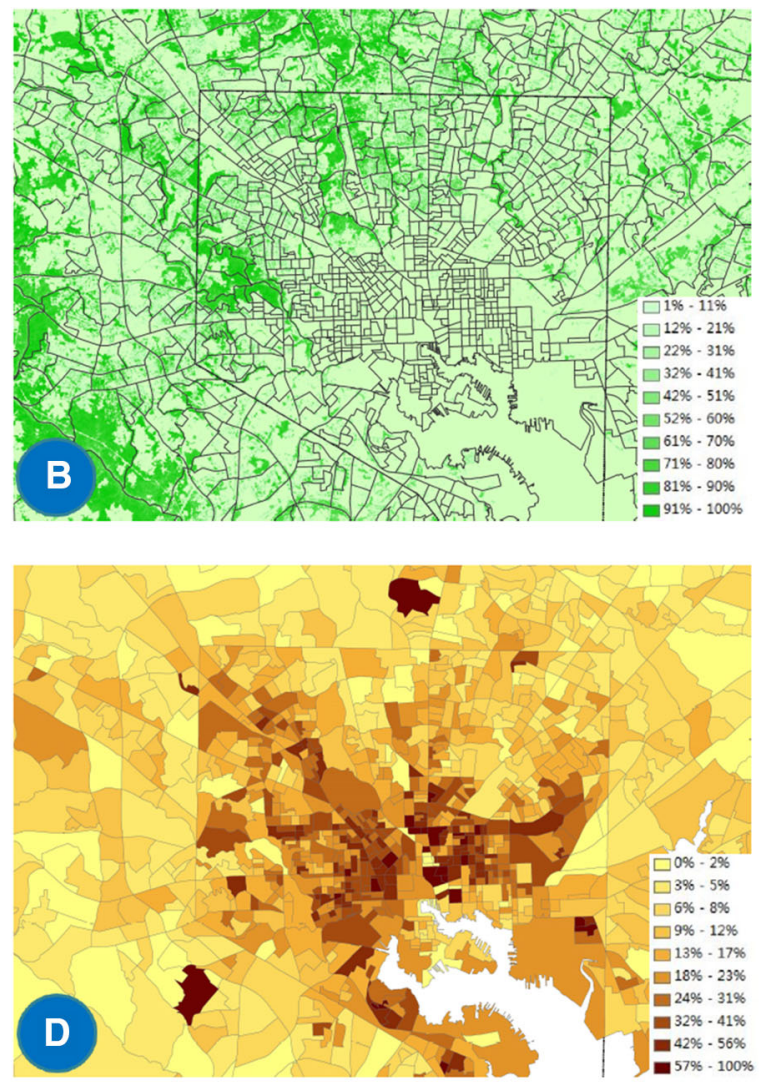

proportion of African American and Latino residents by census block group represented by a gradient of brown fill. d The proportion of residents with incomes classified below the federal poverty level ranging from high to low a gradient of brown fill. e The location of Baltimore City, MD, USA

The urban heat island (UHI) also exemplifies managing integrated social-ecological heterogeneity. From an ecology in cities perspective, urban heat island refers to the phenomenon that cities are 
generally warmer than their surrounding areas. In fact, air and land surface temperatures (LST) within urban areas vary tremendously across space (Huang et al. 2011; Fig. 3a). These variations in LST are significantly related to the uneven distribution of tree canopy in the city (Fig. 3b), not only the large patches of greenspaces, but also those numerous tiny patches of green cover embedded in built areas. More importantly, the unevenly distributed urban tree canopy, and thus the heat islands, were significantly correlated to the spatial distribution of population with different racial and socio-economic status. In general, people of color (Fig. 3c), or in poverty (Fig. 3d) are more likely to live in neighborhoods with higher temperatures (Huang et al. 2011). An ecology of cities approach that focuses on the entire urban mosaic, instead of only the large green patches, is necessary for effective UHI mitigation, as well as for achieving environmental justice (Boone and Fragkias 2012).

A final example is stormwater management beyond urban riparian zones. Urban areas are recognized to be significant and growing contributors to coastal pollution (Peierls et al. 1991). This, in combination with knowledge derived from agricultural landscapes that riparian function could reduce nitrate pollution to coastal and estuarine waters, promoted an ecology in cities strategy for nitrate management. The strategy was basically to restore riparian forest structure, sometimes along with restoration of a more sinuous channel morphology. This strategy may not work, however, if riparian function has been altered in urban landscapes (Cadenasso et al. 2008). In fact, detailed examination of the actual denitrification processes in urban riparian zones indicated that the capacity of those zones was inadequate to the task. The former floodplains, in which the anaerobic conditions and large carbon sources required by denitrifying bacteria were reduced by the "urban stream syndrome," did not support the expected denitrification (Groffman et al. 2003). Altered ecological function in urban riparian zones and the burial of many urban streams motivated a conclusion that additional locations in the entire watershed should be depended on to perform these functions. In essence, the new management strategy was based on expanding the conception of the riparian zone from the stream-side to all locations in the urban watershed where land and water meet (Cadenasso et al. 2008). When managers learned this, they reoriented their management of polluted storm water from a primarily riparian focus to a wholewatershed focus (Hager et al. 2013). This shift required assessing the hybrid nature of patchiness throughout urban watersheds. The hybrid nature of these assessments was emphasized by the need to incorporate the network of storm drain pipes into the spatial delimitation of watershed patches. This approach is likely to be useful in many urban systems, given that urban designers are increasingly concerned with the role of riparian zones in their practice (Musacchio 2009). Like the urban tree canopy goals, engagement with properties and communities far from the streams was deemed necessary to achieve the contribution of nitrate reduction to urban sustainability.

Hybrid heterogeneity under the ecology of cities paradigm supports urban design

Here we turn attention to the relationships of the ecology of the city to the interventions embodied in urban design. Urban design focuses on the architecture, landscape architecture, and social program of intentional, spatially specific architectural and infrastructural interventions in cities, suburbs, and exurbs (Musacchio 2008; Palazzo and Steiner 2011; Shane 2011). It is possible to consider designs to be experiments which, when monitored appropriately, can generate knowledge relevant to improving designs elsewhere (Felson et al. 2013). Indeed, the design process as a creative intervention can involve ecological scientists along with other stakeholders and various design specialists from conception, through visioning, through construction and on to performance evaluation (Felson et al. 2013). We expect an inclusive ecology of the city perspective to be most useful in such interaction.

Design can be motivated by one or more of the three pillars of sustainability-environment, economy, and society (Musacchio 2008), as well as by attention to resilience as a mechanism that supports or thwarts different goals of sustainability (Pickett et al. 2013). Our interest here is to link that focus with the contrasts between the ecology in and the ecology of paradigms. We do not have space to review detailed designs or plans even from an ecological perspective (e.g., see Pickett et al. 2013); however, the shift in paradigms in urban ecology is important because urban designers are becoming increasingly concerned with the 
ecological functionality of their designs (Musacchio 2009; McGrath and Pickett 2011; Felson et al. 2013; Pickett et al. 2013; Steiner 2014). Hence their work can be considered to relate to an inclusive ecology of the city perspective (McGrath 2013), a perspective that encompasses comprehensive and extensive spatial mosaics. Mosaic thinking is a spatially explicit form of systems thinking that recognizes the spatial arrangement of the components of urban ecosystems can have functional significance (Pickett et al. 2016). When mosaic thinking from ecology combines with ideas of the creation of space from a social perspective to suggest that urban patches and urban mosaics are coproduced by biophysical and by social processes (Lachmund 2013). Co-production applies to all forms of intentionality in design as well as to patches in cities, such as some of the extensive green infrastructure of Berlin that owe much of their structure to unsupervised plant colonization and succession (Lachmund 2013).

Ecological design may target specific patches of fine- to medium-scales, but the best ecologicallyaware design encourages the effective interaction of specific projects with the larger, functional urban mosaic (Cadenasso and Pickett 2008; Waldheim 2012; $\mathrm{Wu}$ and $\mathrm{Wu}$ 2013). Greenways, riparian restoration and stream daylighting, tree-lined boulevards slowing automobile traffic and isolating it from muscle-powered traffic are examples of the role of connectivity and spatially extensive context in design. Less grand in scope, but important to the control of stormwater in neighborhoods are such strategies as sharing of bioswales, consolidating impervious surface, and clustering of tree canopy among adjacent parcels in existing neighborhoods (McGrath 2013). Ecological urban design parallels the ecology of cities perspective because it acknowledges that any given project, whether large or small, has an ecosystem context and has structural and functional implications for the larger patch mosaic of urban ecosystems (McGrath 2013; Palazzo and Steiner 2011). Urban design aiming for ecological benefits should deal explicitly with the details of how a project connects with the patch mosaic model of an urban system, and what the reciprocal relationships of the project patch are with adjacent and distant patches in the system (McGrath 2013; Wu and Wu 2013; Niemelä 2014; Wolf and Housley 2014). The neighbor-based low-impact development or retrofitting mentioned above, can be complemented by metropolitan plans and incentives, and by local community social engagement. The larger scales can be encompassed by megaregional visions and operationalized by an inclusive dynamic mosaic or "metacity" model (McGrath and Pickett 2011).

There are other parallels between the concerns of ecology of cities and urban design. They both deal with hybrid patches (Moffatt and Kohler 2008), such that designers are essentially always designing local ecosystems (Cadenasso and Pickett 2008). In addition, both fields require land cover classifications that have sufficient categorical resolution to provide projects with an appropriately detailed context for individual patches. For example, designing residential projects as hybrids of vegetation, surface covers, and buildings rather than as examples of low, medium, or high density, may yield different results. A case in point is the conversion of a multistory warehouse to housing in Hoboken NJ was designed to expose the control of stormwater in this low elevation site, as well as disperse use of water and installation of productive and ornamental greenspace on roof and adjacent plaza (Marshall 2013). Hybrid designs include the relatively fine scale green infrastructure shared by neighbors mentioned above, as well as more substantial green infrastructure suffused throughout a community. The contemporary ecology of cities shares with ecological urban design an interest in how urban heterogeneity is represented (McGrath et al. 2007). These disciplines share (1) the need for refined categories to understand patch structure (Shane 2011), (2) a view that patches are biophysical-built-social hybrids (Moffatt and Kohler 2014), and (3) a deep interest in promoting sustainability (Beatley 2000). Because sustainability requires focusing ecological, social, and economic lenses on the same places, it becomes a shared goal of urban ecology and urban design (Steiner 2014).

\section{Conclusion}

Tracing the concepts, models, and applications of two contrasting paradigms for the study of urban ecological science has exposed different approaches to urban heterogeneity and their divergent implications for sustainability. The traditional framework for measuring spatial heterogeneity under the classical ecology in the city paradigm supports a narrow view of sustainability that focuses on the persistence and viability of 
biologically dominated patches in cities, towns, and suburbs. There are many intrinsic and social benefits that derive from the persistence of green patches and networks of green patches in the urban fabric, and the ecology in cities approach supports those services. However, a more complete view of sustainability, one that encompasses the requisite biophysical, social, and economic processes, is better supported by a new framework under an ecology of cities paradigm. This paradigm has encouraged the modeling of hybrid patches, and the assembly of those patches into dynamic spatial mosaics that exhaustively represent an urban area. There are new remote sensing platforms, image analysis tools, and land cover classification methodologies that support these new conceptions and models. The ecology of cities paradigm and the concepts and tools it supports are a novel, practical application of the social-ecological systems framework, which link with pressing concerns for increased sustainability in urban management and design.

Acknowledgments This research was funded by the National Natural Science Foundation of China (Grant No. 41371197 and 41422104) and the One Hundred Talents program. The support of the U.S. National Science Foundation LTER program (Grant DEB 042376), CAREER program (DEB-0844778), and Urban Sustainability Research Coordination Network (RCN 1140070) is also gratefully acknowledged.

\section{References}

Adams LW (2005) Urban wildlife ecology and conservation: a brief history of the discipline. Urban Ecosyst 8:139-156

Band L, Cadenasso M, Grimmond CS, Grove JM, Pickett STA (2005) Heterogeneity in urban ecosystems: patterns and process. In: Lovett G, Turner M, Jones C, Weathers K (eds) Ecosystem function in heterogeneous landscapes. Springer, New York, pp 257-278

Beatley T (2000) Green urbanism: learning from European cities. Island Press, Washington, DC

Ben-Joseph E (2005) The code of the city: standards and the hidden language of place making. MIT Press, Cambridge

Boone CG, Fragkias M (2012) Urbanization and sustainability: linking urban ecology, environmental justice and global environmental change. Springer, New York

Breuste J, Feldmann H, Uhlmann O (eds) (1998) Urban ecology. Springer, New York

Buijs S, Tan W, Tunas D (2010) Three pillars of megacities. In: Buijs S, Tan W, Tunas D (eds) Megacities: exploring a sustainable future. 010 Publishers, Rotterdam, pp 190-200

Burger JR, Allen CD, Brown JH, Burnside WR, Davidson AD, Fristoe TS, Hamilton MJ, Mercado-Silva N, Nekola JC,
Okie JG, Zuo W (2012) The macroecology of sustainability. PLoS Biol 10:e1001345

Buyantuyev A, Wu J, Gries C (2010) Multiscale analysis of the urbanization pattern of the Phoenix metropolitan landscape of USA: time, space and thematic resolution. Landsc Urban Plan 94(3-4):206-217

Cadenasso ML (2013) Designing ecological heterogeneity. Urban design ecologies: AD reader. Wiley, Hoboken, pp 271-281

Cadenasso ML \& Pickett STA (2008) Urban principles for ecological landscape design and management: scientific fundamentals. Cities Environ 1(2):Article 4

Cadenasso ML, Pickett STA, Weathers KC, Jones CG (2003) A framework for a theory of ecological boundaries. Bioscience 53:750-758

Cadenasso ML, Pickett STA, Grove JM (2006) Dimensions of ecosystem complexity: heterogeneity, connectivity, and history. Ecol Complex 3:1-12

Cadenasso ML, Pickett STA, Schwarz K (2007) Spatial heterogeneity in urban ecosystems: reconceptualizing land cover and a framework for classification. Front Ecol Environ 5:80-88

Cadenasso ML, Pickett STA, Groffman P, Band LE, Brush GS, Galvin MF, Grove JM, Hagar G, Marshall V, McGrath BP, O'Neil-Dumme JPM, Stack WP, Troy AR (2008) Exchanges across land-water-scape boundaries in urban systems strategies for reducing nitrate pollution. Ann N Y Acad Sci 1134:213-232

Carpenter SR, Westley F, Turner MG (2005) Surrogates for resilience of social-ecological systems. Ecosystems 8:941-944

Childers DL, Pickett STA, Grove JM, Ogden L, Whitmer A (2014) Advancing urban sustainability theory and action: challenges and opportunities. Landsc Urban Plan 125:320-328

Chowdhury R, Larson K, Grove JM, Polsky C, Cook E, Onsted J, Ogden L (2011) A multi-scalar approach to theorizing socio-ecological dynamics of urban residential landscapes. Cities Environ 4:6

Curwell S, Deakin M, Symes M (eds) (2005) Sustainable urban development: the framework and protocols for environmental assessment, vol 1. Routledge, New York

Douglas I, James P (2015) Urban Ecology. Routledge, New York

Ehrenfeld JG (2000) Evaluating wetlands within an urban context. Ecol Eng 15:253-265

Felson AJ, Bradford MA, Terway TM (2013) Promoting Earth stewardship through urban design experiments. Front Ecol Environ 11(7):362-367

Forman RTT (1995) Land mosaics: the ecology of landscapes and regions. Cambridge University Press, New York

Gaston K (2010) Urban ecology. Cambridge University Press, New York

Golubiewski NE (2006) Urbanization increases grassland carbon pools: effects of landscaping in Colorado's front range. Ecol Appl 16:555-571

Grimm NB, Grove JM, Pickett STA, Redman CL (2000) Integrated approaches to long-term studies of urban ecological systems. Bioscience 50:571-584

Grimm NB, Faeth SH, Golubiewski NE, Redman CL, Wu J, Bai X, Briggs JM (2008) Global change and the ecology of cities. Science 319:756-760 
Groffman PM, Bain DJ, Band LE, Belt KT, Brush GS, Grove JM, Pouyat RV, Yesilonis IC, Zipperer WC (2003) Down by the riverside: urban riparian ecology. Front Ecol Environ $1: 315-321$

Grove JM, Burch WR (1997) A social ecology approach and applications of urban ecosystem and landscape analyses: a case study of Baltimore, Maryland. Urban Ecosyst $1: 259-275$

Grove JM, Locke DH, O’Neil-Dunne JPM (2014) An Ecology of prestige in New York City: examining the relationships among population density, socio-economic status, group identity, and residential canopy cover. Environ Manag 54:402-419

Haase D, Frantzeskaki N, Elmqvist T (2014) Ecosystem services in urban landscapes: practical applications and governance implications. Ambio 43:407-412

Hager GW, Belt KT, Stack W, Burgess K, Grove JM, Caplan B, Hardcastle M, Shelley D, Pickett STA, Groffman PM (2013) Socioecological revitalization of an urban watershed. Front Ecol Environ 11:28-36

Huang GL, Zhou WQ, Cadenasso ML (2011) Is everyone hot in the city? spatial pattern of land surface temperatures, land cover and neighborhood socioeconomic characteristics in Baltimore, MD. J Environ Manag 92(7):1753-1759

Irwin EG (2010) New directions for urban economic models of land use change: incorporating spatial dynamics and heterogeneity. J Reg Sci 50:65-91

Jenerette GD, Wu J (2001) Analysis and simulation of land-use change in central Arizona-Phoenix region, USA. Landscape Ecol 16:611-626

Jenerette GD, Wu J, Grimm NB, Hope D (2006) Points, patches, and regions: scaling soil biogeochemical patterns in an urbanized arid ecosystem. Glob Chang Biol 12:1532-1544

Jenks M, Jones C (eds) (2010) Dimensions of the sustainable city. Springer, New York

Kong F, Yin H, Nakagoshi N, Zong Y (2010) Urban green space network development for biodiversity conservation: identification based on graph theory and gravity modeling. Landsc Urban Plan 95:16-27

Koskela L (2008) Is a theory of the built environment needed? Build Res Inf 36:211-215

Lachmund J (2013) Greening Berlin. MIT Press, Cambridge

Larondelle N, Hamstead ZA, Kremer P, Haase D, McPhearson T (2014) Applying a novel urban structure classification to compare the relationships of urban structure and surface temperature in Berlin and New York City. Appl Geogr 53:427-437

Locke D, Grove JM, Lu JWT, Troy AR, O'Neil-Dunne JPM, Beck BD (2010) Prioritizing preferable locations for increasing urban tree canopy in New York City. Cities Environ 3:Article 4

Luck M, Wu J (2002) A gradient analysis of urban landscape pattern: a case study from the Phoenix metropolitan region, Arizona, USA. Landscape Ecol 17:327-339

Machlis GE, Force JE, Burch WR (1997) The human ecosystem. 1. The human ecosystem as an organizing concept in ecosystem management. Soc Nat Resour 10:347-367

Marshall V (2013) Aesthetic resilience. In: Pickett STA, Cadenasso ML, McGrath B (eds) Resilience in ecology and urban design: linking theory and practice for sustainable cities. Springer, New York, pp 319-329
McDonnell MJ, Hahs AK (2008) The use of gradient analysis studies in advancing our understanding of the ecology of urbanizing landscapes: current status and future directions. Landscape Ecol 23:1143-1155

McDonnell MJ, Hahs A (2009) Comparative ecology of cities and towns: past, present and future. In: McDonnell MJ, Hahs A, Breuste J (eds) Ecology of cities and towns: a comparative approach. Cambridge University Press, New York, pp 71-89

McDonnell MJ, Pickett STA, Groffman P, Bohlen P, Pouyat RV, Zipperer WC, Parmelee RW, Carreiro MM, Medley K (1997) Ecosystem processes along an urban-to-rural gradient. Urban Ecosyst 1:21-36

McGrath B (2013) Slow, moderate, fast: urban adaptation and change. In: Pickett STA, Cadenasso ML, McGrath B (eds) Resilience in ecology and urban design: linking theory and practice for sustainable cities. Springer, New York, pp 231-252

McGrath B, Pickett STA (2011) The metacity: a conceptual framework for integrating ecology and urban design. Challenges 2011(2):55-72

McGrath BP, Marshall V, Cadenasso ML, Grove JM, Pickett STA, Plunz R, Towers J (eds) (2007) Designing patch dynamics. Columbia University Graduate School of Architecture, Preservation and Planning, New York

McIntyre NE, Knowles-Yánez K, Hope D (2000) Urban ecology as an interdisciplinary field: differences in the use of "urban" between the social and natural sciences. Urban Ecosyst 4:5-24

McPhearson T, Pickett STA, Grimm NB, Niemala J, Alberti M, Elmqvist T, Weber C, Breuste J, Haase D, Quereshi S (2016) Advancing urban ecology towards a science of cities. Bioscience 66:198-212

Medley KE, McDonnell MJ, Pickett STA (1995) Forest-landscape structure along an urban-to-rural gradient. Prof Geogr 47:159-168

Moffatt S, Kohler N (2008) Conceptualizing the built environment as a social-ecological system. Build Res Inf $36: 248-268$

Musacchio LR (2008) Metropolitan landscape ecology: using tranlsational research to increase sustainability, resilience, and regeneration. Landsc $\mathrm{J} 27: 1-8$

Musacchio LR (2009) The scientific basis for the design of landscape sustainability: a conceptual framework for translational landscape research and practice of designed landscapes and the six Es of landscape sustainability. Landscape Ecol 24:993-1013

Niemelä J (2014) Ecology of urban green spaces: the way forward in answering major research questions. Landsc Urban Plan 125:298-303

Palazzo D, Steiner F (2011) Urban ecological design: a process for regenerative places. Island Press, Washington, DC

Peierls BL, Caraco NF, Pace ML, Cole JJ (1991) Human influence on river nitrogen. Nature 350:386-387

Pickett STA (2010) The wild and the city. In: Redford KH, Fearn E (eds) State of the wild: a global portrait 2010 . Island Press, Washington, DC, pp 153-159

Pickett STA Jr, Burch WR, Dalton SE, Foresman TW (1997) Integrated urban ecosystem research. Urban Ecosyst $1: 183-184$

Pickett STA, Cadenasso ML (1995) Landscape ecology: spatial heterogeneity in ecological systems. Science 269:331-334 
Pickett STA, Cadenasso ML, Grove JM, Groffman PM, Band LE, Boone G, Burch WR, Grimmond SB, Hom J, Jenkins JC, Law NL, Nilon CH, Pouyat RV, Szlavecz K, Warren PS, Wilson MA (2008) Beyond urban legends: an emerging framework of urban ecology as illustrated by the Baltimore Ecosystem Study. Bioscience 58:139-150

Pickett STA, Cadenasso ML, McGrath B (eds) (2013) Resilience in ecology and urban design: linking thoery and practice for sustainable cities. Springer, New York

Pickett STA, Cadenasso ML, Rosi-Marshall EJ, Belt KT, Groffman PM, Grove JM, Irwin EG, Kaushal SS, LaDeau SL, Nilon CH, Swan CM, Warren PS (2016) Dynamic heterogeneity: a framework to promote ecological integration and hypothesis generation in urban systems. Urban Ecosyst 34:1-14

Pickett STA, Zhou W (2015) Global urbanization as a shifting context for applying ecological science toward the sustainable city. Ecosyst Health Sustain 1:1-15

Pincetl S (2010) From the sanitary to the sustainable city: challenges to institutionalizing biogenic (nature's services) infrastructure. Local Environ 15:43-58

Platt RH, Rowntree RA, Muick PC (1994) The ecological city: preserving and restoring urban biodiversity. University of Massachusetts Press, Amherst

Qian Y, Zhou W, Li W, Han L (2015a) Understanding the dynamic of greenspace in the urbanized area of Beijing based on high resolution satellite images. Urban For Urban Green 14:39-47

Qian Y, Zhou W, Yu W, Pickett STA (2015b) Quantifying spatiotemporal pattern of urban greenspace: new insights from high resolution data. Landscape Ecol 7:1165-1173

Redman CL (2014) Should sustainability and resilience be combined or remain distinct pursuits? Ecol Soc 19:37

Scheiner SM, Willig MR (2011) A general theory of ecology. In: Scheiner SM, Willig MR (eds) The theory of ecology. University of Chicago Press, Chicago, pp 3-18

Shane DG (2011) Urban design since 1945 - a global perspective. Chichester, Wiley, p 360

Stearns FW, Montag T (1974) The urban ecosystem - a holistic approach. Dowden, Hutchinson \& Ross, Inc, Stroudsburg

Steiner F (2014) Frontiers in urban ecological design and planning research. Landscape Urban Plan 125:304-311

Sukopp H, Numata M, Huber A (1995) Urban ecology as the basis of urban planning. SPB Academic Publishing, The Hague

Sukopp H, Weiler S (1988) Biotope mapping and nature conservation strategies in urban areas of the Federal-Republicof-Germany. Landscape Urban Plan 15:39-58

Troy AR, Grove JM, O'Neil-Dunne JPM, Pickett STA, Cadenasso ML (2007) Predicting opportunities for greening and patterns of vegetation on private urban lands. Environ Manag 40:394-412

Turner BL II (2010) Vulnerability and resilience: coalescing or paralleling approaches for sustainability science? Glob Environ Change 20:570-576

Turner MG, Gardner RH, O’Neill RV (2001) Landscape ecology in theory and practice. Springer, New York

Waldheim C (2012) The landscape urbanism reader. Chronicle Books, San Francisco
Walker B, Holling CS, Carpenter SR, Kinzig A (2004) Resilience, adaptability and transformability in social-ecological systems. Ecol Soc 9:Article 5

Wolf KL, Housley E (2014) Environmental equality: providing nearby nature for everyone. TKF Foundation, Annapolis

Wu J (2002) A spatially explicit hierarchical approach to modeling complex ecological systems: theory and applications. Ecol Model 153:7-26

Wu J (2010) Urban sustainability: an inevitable goal of landscape research. Landscape Ecol 25:1-4

Wu J (2014) Urban ecology and sustainability: the state-of-thescience and future directions. Landscape Urban Plan 125:209-221

Wu J, Wu T (2013) Ecological resilience as a foundation for urban design and sustainability. In: Pickett STA, Cadenasso ML, McGrath B (eds) Resilience in ecology and urban design: linking theory and practice for sustainable cities. Springer, New York, pp 211-229

Wu W (2013) Landscape sustainability science: ecosystem services and human well-being in changing landscapes. Landscape Ecol 28(6):999-1023

Yaro RD, Hiss T (1996) A Region at Risk: the third regional plan for the new York-New Jersey-Connecticut metropolitan area. Island Press, Washington, DC

Yohe G, Tol RSJ (2002) indicators for social and economic coping capacity - moving toward a working definition of adaptive capacity. Glob Environ Chang 12:25-40

Zhou W, Cadenasso ML, Schwarz K, Pickett STA (2014) Quantifying spatial heterogeneity in urban landscapes: integrating visual interpretation and object-based classification. Remote Sens 6:3369-3386

Zhou W, Huang G, Cadenasso ML (2011a) Does spatial configuration matter? understanding the effects of land cover pattern on land surface temperature in urban landscapes. Landscape Urban Plan 102(1):54-63

Zhou W, Huang G, Pickett STA, Cadenasso ML (2011b) 90 years of forest cover change in an urbanizing watershed: spatial and temporal dynamics. Landscape Ecol 26:645-659

Zhou W, Schwarz K, Cadenasso ML (2010) Mapping urban landscape heterogeneity: agreement between visual interpretation and digital classification approaches. Landscape Ecol 25:53-67

Zhou W, Troy AR (2008) An object-oriented approach for analyzing and characterizing urban landscape at the parcel level. Int J Remote Sens 29:3119-3135

Zhou W, Troy AR, Grove JM (2008) Modeling residential lawn fertilization practices: integrating high resolution remote sensing with socioeconomic data. Environ Manag 41:742-752

Zipperer WC, Wu JG, Pouyat RV, Pickett STA (2000) The application of ecological principles to urban and urbanizing landscapes. Ecol Appl 10:685-688

Zurlini G, Petrosillo I, Jones KB, Zaccarelli N (2013) Highlighting order and disorder in social-ecological landscapes to foster adaptive capacity and sustainability. Landscape Ecol 28:1161-1173 